\title{
DEVELOPMENT OF A NATIONAL LICENCE ASSESSMENT PROGRAM FOR OLDER DRIVERS IN AUSTRALASIA
}

\author{
Brian Fildes, Nicky Pronk, Judith Charlton \\ Monash University Accident Research Centre \\ Clayton, 3800, Australia \\ E-mail: brian.fildes@general.monash.edu.au \\ Jim Langford \\ Department of Infrastructure, Energy and Resources \\ Tasmania, Australia \\ Bill Frith \\ Land Safety Traffic Authority, New Zealand
}

\begin{abstract}
Summary: Licensing requirements in Australasia vary across jurisdictions with little evidence of any safety benefit for any existing procedure. In 1998, Austroads (a collaboration of State Traffic Authorities in Australia and New Zealand) commissioned the Monash University Accident Research Centre to develop and trial a model licence re-assessment program for older drivers in Australasia. The procedure was developed in 1999 and involved input from a number of key experts in Australia and New Zealand. A pilot study was undertaken in Tasmania early in 2000 to evaluate the procedural aspects of the model. A study of four off-road screening tests also commenced in 2001 to validate these instruments against a range of driving performance measures. This paper reports preliminary findings from these studies.
\end{abstract}

Re-licensing requirements for older drivers in Australia and New Zealand vary across jurisdictions, with most requiring some form of age-based re-assessment. Some jurisdictions, however, have no such requirement, relying on the community to refer suspected at-risk individuals. Evidence from the mid-1980s suggests that older driver crash rates may be no different for these states than those with mandatory age-based testing. In addition, many older people feel that age-based testing is discriminatory and a more acceptable approach may be to focus on functional ability.

Australian State and New Zealand traffic authorities commissioned the Monash University Accident Research Centre to develop a model licence re-assessment procedure for older drivers. A challenge for the model was to balance mobility needs for older people and safety. The model was to be functionally based and to mirror similar developments in the USA by the National Highway Traffic Safety Administration.

Advisory committees were formed in Australia and New Zealand involving key stakeholders to work with the researchers to develop a more effective and acceptable model procedure. A number of critical components of the model were identified, including:

- $\quad$ older driver testing based on functional ability rather than chronological age;

- development of a network of community referral sources;

- use of multi-tiered assessment procedures and instruments;

- use of a case officer to assist older people through the assessment process;

- use of re-training and rehabilitation procedures where appropriate; and 
- expansion of the licensing authority's role to include counselling on alternative mobility options, whenever appropriate.

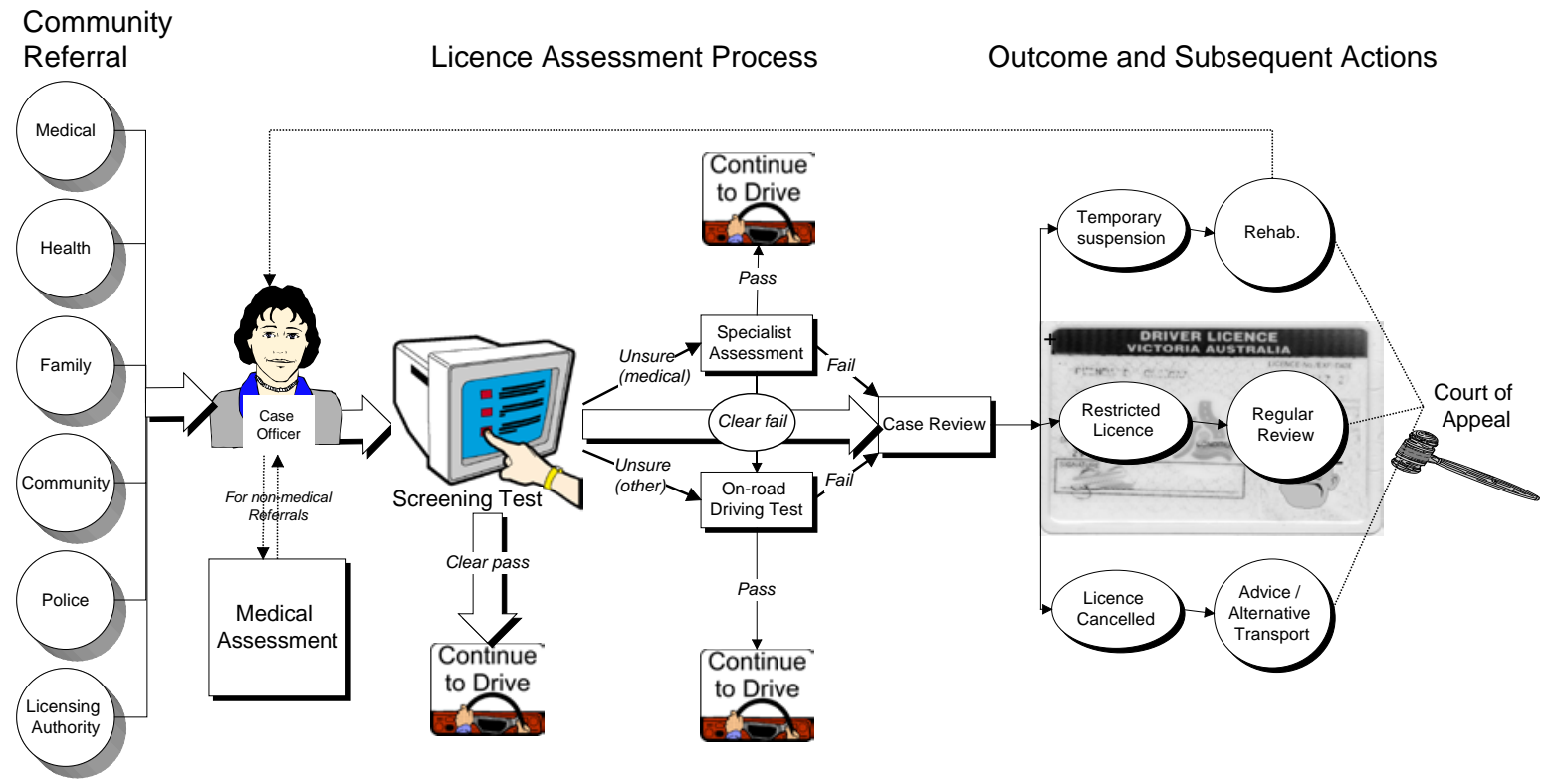

Figure 1 - Outline of the Model Licensing Re-Assessment Procedure for Older Drivers

Figure 1 shows an outline of the proposed model encompassing the key criteria specified above. Full details of the model can be found in Fildes et al (2000). Stage 2 involved two steps; (1) a pilot study of the procedure in a licensing environment, and (2), an evaluation of a number of screening tests (described below).

\section{STAGE 2: RESEARCH PROGRAM}

\section{Pilot Study of the Model}

The first task in this phase of the research program was to pilot test the model procedure in a licensing environment to evaluate its usefulness and acceptability by both licensing agents and older drivers themselves. This was undertaken in the State of Tasmania, Australia, where currently age-based (older driver) re-assessments are requirement.

Fifty-six older drivers agreed to participate in the study ( $\mathrm{N}=37$ male and $\mathrm{N}=19$ female) and their ages ranged from 85 years to 94 years (median= 86 years). At the time of presenting for their licence re-assessment most drivers (83.9\%) already held some form of restricted driving licence (eg: 95.7\% were required to wear glasses when driving). All drivers who volunteered to participate in the study had been deemed fit to drive by a medical practitioner.

A number of office-based older driver screening tests have been developed overseas (see Fildes, et al., 2000 for a summary). The Gross Impairments Screening Battery of General Physical and Mental Abilities (GRIMPS) screening test (Scientex, Washington) was chosen for inclusion in the study. This paper and pencil test measures a number of skills and abilities that are believed to be important for the driving task including tests of cognitive and gross motor functioning. Currently, this test is being used in a similar study in Maryland, USA. The standard Tasmanian on-road driving test was re-structured to include an on-road test procedure for older drivers recently designed and introduced in New Zealand. 
Participants were scored simultaneously using both the Tasmanian and New Zealand scoring criteria. On completion of both processes, participants completed a questionnaire exploring their level of satisfaction with the new processes.

Results. The results of the process evaluation showed that the majority of participants were able to complete the screening test within 40 minutes. Only one participant failed to complete the GRIMPS test. The regular testing officers for this jurisdiction conducted the on-road driving test. Scores for this test were based on the standard Tasmanian on-road scoring criteria. In addition, the case officer sat in the back of the car and scored the test using the New Zealand criteria. These two sets of data provide the possibility for a comparison of on-road driving tests. The average time to complete the driving test was 30 minutes. The New Zealand driving test scoring criteria failed a far greater number of participants than the existing on-road, licensing test.

All participants reported that the GRIMPS test was acceptable however some indicated that they would like feedback about their performance and others felt that some of the items were too simple. Only one participant claimed it was not a better test of driving competence than an actual driving test. In total, $98 \%(\mathrm{~N}=51)$ of participants indicated that they had found the onroad driving test to be acceptable. Four drivers added that they found it to be "much harder than usual" or "had other difficulties with the road layout".

Participants were asked whether they had experienced any difficulties with the licence reassessment process. In total, 5.7\% (of $\mathrm{N}=53$ ) indicated that they had experienced some difficulty during the process. However, the majority of participants (96.2\% of respondents) stated that they found the overall process of licence re-assessment (as part of the study) to be acceptable. In addition to this, a number of older drivers were not aware of alternative transport options in their local area. This is an issue of concern.

Almost 98\% of respondents indicated that they had found the case officer helpful during the licence re-assessment process. Their feedback indicated that several of the older drivers had used the case officer position as a resource leading up to or following their assessment (e.g. to ask questions relating to the assessment, to check up on things, or if they were upset following the test). One of the key aims of the case officer position in the model is to make the system more acceptable to older people and offer support where required. It is promising that some older people did use this resource and that the feedback has been positive.

\section{Screening Test Evaluation.}

The next step of the Stage 2 Research Program was to identify a suitable off-road screening test that could be administered to older drivers in a licensing office to predict their on-road safety risk. The screening test was central to the model licence re-assessment procedure, which sought to predict on-road safety risk in an off-road office environment. The advantage of a screening test is to minimise the necessity of taking potentially unsafe drivers on the road and putting the individual, the licence assessor and the general public in danger. There have been examples of severe crashes in this country that have occurred during the assessment of an older driver's fitness to drive.

A number of potential older driver screening tests were identified. Four of these were selected for the study, namely: 
- $\quad$ The GRIMPS test. See description above.

- $\quad$ The EDS (Elemental Driving Simulator) test (Life Science and Associates, NY) requires participants to undergo a computer-tracking task.

- $\quad$ The CALTEST (DMV, California) is a touch-screen computer test of attention, visual and cognitive abilities shown to be associated with an increase risk of crashing (Janke, 1994). This test was supplemented with a video hazard perception test developed by VicRoads in Victoria, Australia.

- The DriveABLE is a touch-screen computer test (DriveABLE Inc., Edmonton, Canada) of attention, vision and cognitive abilities.

Each of these four tests has undergone preliminary evaluation looking at associations between screening test performance and on-road driving ability but little information is available on associated crash risk.

A randomised control trial commenced in Wellington, New Zealand in February 2001 and by May, approximately 400 participants will have completed the evaluation. All participants (80years and older) met the requirements for licence re-assessment in New Zealand. As part of this process they were required to undertake a medical examination and undergo an on-roaddriving test. Participants were recruited from licence office records, and completed one of the four tests. During the study, they also completed a survey collecting demographic information, self-reported health status, and self-reported crash and infringement history. In addition, the licensing authority provided official statistics for each participant's on-road test results, crash history and medical status.

Results. A preliminary analysis of the participant's screening test results with the battery of performance measures will be undertaken during June 2001 to assess the required sample size for statistical robustness.

Based on figures to date, $61.9 \%$ of approached older drivers agreed to participate in the study. The average time for participants to complete each of the screening tests are as follows; GRIMPS (35 minutes), EDS (55 minutes), CALTEST (47 minutes) and DriveABLE (60 minutes). To date, $75 \%$ of participants reported the screening test they undertook was satisfactory, although there were wide differences in satisfaction and ease of operation between each of the tests.

\section{DISCUSSION}

During the first stage of an Austroads funded project a model licence re-assessment procedure for older and disabled drivers was developed. A second stage of the research program was undertaken to pilot test the procedure in a licensing environment and evaluate four off-road screening tests in terms of their capability to predict at-risk older drivers in an office environment.

Results of the evaluation of the model procedure indicate that the process was well received by older drivers. The screening test was accepted by the older drivers involved with the study. Several older drivers noticed that the driving test was more detailed and thorough than previous tests undertaken but there was an overall acceptance of procedures. The older drivers indicated that they found the case officer to be helpful and several used this position as a resource leading up to and after their assessment. Survey results suggest many older drivers are not well informed 
about alternative transport options available to them. This is an area that will clearly require more attention in the future as the population ages.

The evaluation of the four screening tests was undertaken to test their ability to predict on-road behaviour. Each of the four chosen tests addressed what is currently considered to be the critical aspects of age-related disability and poor driving performance, namely visual decline (field of view and dynamic acuity) and reduced cognitive capacity and mental disease. While these tests generally had been tested against on-road driving performance, they had not been evaluated against a range of on-road safety criteria. Moreover, little was known about their relative performance when used in a licensing environment.

The screening test evaluation study is on going at the moment and final results are not yet available. However, preliminary findings show differences in the time taken to administer each test as well as the degree of difficulty experienced by the participants. Future work planned for this study includes analyses to examine associations between performance on the screening tests and crash involvement (self reported and official), recent infringement history, performance on the New Zealand older driver on-road driving test, and a range of other measures including health status.

A third phase of the project is planned involving a full trial of the model licence re-assessment procedure in one or more Australasian jurisdictions.

\section{REFERENCES}

Fildes, B., Pronk, N., Langford, J., Hull, M., Frith, B., \& Anderson, R. (2000). Model Licence Re-Assessment Procedure for Older and Disabled Drivers. AP-R176, Austroads Inc, Australia.

Janke M. (1994). Age-related disabilities that may impair driving and their assessment: a literature review, Californian Department of Motor Vehicles, Sacramento, USA. 